\title{
Sensitivity of biogenic volatile organic compound emissions to leaf area index and land cover in Beijing
}

\author{
Hui Wang ${ }^{1,4}$, Qizhong Wu ${ }^{1,4}$, Hongjun Liu ${ }^{2}$, Yuanlin Wang ${ }^{3,4}$, Huaqiong Cheng ${ }^{1,4}$, Rongrong Wang ${ }^{1,4}$, \\ Lanning Wang ${ }^{1,4}$, Han Xiao ${ }^{1,4}$, and Xiaochun Yang ${ }^{1,4}$ \\ ${ }^{1}$ College of Global Change and Earth System Science, Beijing Normal University, Beijing 100875, China \\ ${ }^{2}$ Department of Physics, Beijing Normal University, Beijing 100875, China \\ ${ }^{3}$ State Key Laboratory of Atmospheric Boundary Layer Physics and Atmospheric Chemistry, \\ Institute of Atmospheric Physics, Chinese Academy of Sciences, Beijing 100029, China \\ ${ }^{4}$ Joint Center for Global Changes Studies, Beijing Normal University, Beijing 100875, China
}

Correspondence: Qizhong Wu (wqizhong@bnu.edu.cn)

Received: 11 October 2017 - Discussion started: 15 December 2017

Revised: 14 June 2018 - Accepted: 21 June 2018 - Published: 9 July 2018

\begin{abstract}
The Beijing area has suffered from severe air pollution in recent years, including ozone pollution in the summer. In addition to the anthropogenic emissions inventory, understanding local ozone pollution requires a reliable biogenic volatile organic compound (BVOC) emission inventory. Forest coverage rose from 20.6 to $35.8 \%$ from 1998 to 2013 in Beijing according to the National Forest Resource Survey (NFRS), and accurate representations of land cover for recent years is crucial for estimating BVOC emissions and their impacts on air quality. In this study, we established a high-resolution BVOC emission inventory in Beijing using the Model of Emissions of Gases and Aerosols from Nature (MEGAN) v2.1 with three independent leaf area index (LAI) products and three independent land cover products. Various combinations of the Global LAnd Surface Satellite (GLASS), Moderate-Resolution Imaging Spectroradiometer (MODIS) MCD15, and GEOland (GEO) v2 LAI datasets and the Finer Resolution Observation and Monitoring of Global Land Cover (FROM-GLC), MODIS MCD12Q1 plant functional type (PFT) products, and Climate Change Initiative Land Cover (CCI LC) products are used in five model sensitivity experiments (E1-E5), and the experiment using the FROM-GLC with the highest spatial resolution of $30 \mathrm{~m}$ and GLASS LAI products was treated as the baseline. These sensitivity calculations were driven by hourly, $3 \mathrm{~km}$ meteorological fields from the Weather Research and Forecasting (WRF) model. The following results were obtained: (1) according to the baseline estimate, the total amount of BVOC
\end{abstract}

emissions is $75.9 \mathrm{Gg}$ for the Beijing area, and isoprene, monoterpenes, sesquiterpenes and other VOCs account for 37.6, 14.6, 1.8 and $46 \%$ of the total, respectively. Approximately three-quarters of BVOC emissions occur in the summer. (2) According to the sensitivity experiments, the LAI input does not significantly affect the BVOC emissions. Using MODIS MCD15Q1 and GEO v2 LAI led to slight declines of 2.6 and $1.4 \%$, respectively, of BVOC emissions in the same area. (3) The spatial distribution of PFTs from different inputs strongly influenced the spatial distribution of BVOC emissions. Furthermore, the cross-walking table for converting land cover classes to PFTs also has a strong impact on BVOC emissions; the sensitivity experiments showed that the estimate of BVOC emissions by CCI LC ranged from 42.1 to $70.2 \mathrm{Gg}$ depending on the cross-walking table used.

\section{Introduction}

Biogenic volatile organic compounds (BVOCs) play a significant role in the atmospheric environment because of the large quantities emitted and their high reactivity (Fuentes et al., 2000; Guenther et al., 1995). BVOCs can form secondary organic aerosol (SOA) (Claeys et al., 2004; Kavouras et al., 1998) as well as affect tropospheric ozone $\left(\mathrm{O}_{3}\right)$ and nitrogen oxide radicals $\left(\mathrm{NO}_{x}\right)$ (Fuentes et al., 2000; Seinfeld and Pandis, 2012). BVOC emissions are affected by meteorological conditions, including solar radiation, temperature and 
concentration of carbon dioxide (Arneth et al., 2007; Guenther et al., 2006; Guenther et al., 1993). Furthermore, the changing climate will lead to changes in environmental conditions and anthropogenic activities, which have an impact on the BVOC emissions, leading to feedback effects on climate and human beings (Penuelas and Staudt, 2010). Under the influence of global warming, as estimated by Stavrakou et al. (2014), the isoprene emissions in East Asia and China increased by 0.2 and $0.5 \% \mathrm{yr}^{-1}$, respectively, from 1979 to 2005. In addition, considering the severe air quality problem in China, addressing the contribution from natural and anthropogenic sources could benefit attempts to improve air quality.

Klinger et al. (2002) estimated the total amount of BVOC emissions in China at about $21.0 \mathrm{Tg}$, with terpenoids accounting for approximately $8.06 \mathrm{Tg}$. That terpenoid emission estimate is similar to the $10.9 \mathrm{Tg}$ estimated by Tie et al. (2006). Since subtropical regions in China have severe ozone pollution and abundant forests, multiple studies have focused on local biogenic emissions and their potential effects on urban air quality (Wang et al., 2011, 2013; Leung et al., 2010). As a typical city in northern China, Beijing faces severe ozone pollution in summer (Wang et al., 2006; Safieddine et al., 2016; Zhao et al., 2010). Furthermore, model and satellite results both indicate that the North China Plain suffers relatively more severe $\mathrm{O}_{3}$ pollution than southern regions in China during summer (Zhao et al., 2010; Safieddine et al., 2016). Because Beijing is surrounded by temperate forests, it is necessary to consider the influence from biogenic emissions on local air pollution. Previous studies have carried out some calculations of local BVOC emissions (Wang et al., 2003; Klinger et al., 2002), but these estimates were made for an earlier period (19982000), and the China Forestry Database (http://data.forestry. gov.cn/lysjk) provided by the National Forest Resources Surveys shows that the forest coverage rate in Beijing rose from 20.6 to $35.8 \%$ from 1998 to 2013. Furthermore, the dominant tree species of the local forests are Quercus and Populus, which are strong isoprene emitters (Wang et al., 2003). Therefore, an up-to-date BVOC emission inventory is needed to evaluate biogenic effects on local air quality.

The Model of Emission of Gases and Aerosols from Nature (MEGAN) (Guenther et al., 2006, 2012) is the most commonly used BVOC emission model and has been widely used in air quality simulations in China (Gao et al., 2016; Geng et al., 2011; Fu and Liao, 2012; Wang et al., 2018). In this study, we adopted the MEGAN model to estimate BVOC emissions across the Beijing region. The leaf area index (LAI) and land cover (LC) are two important factors for the BVOC emission estimates. The LAI and LC determine the biomass and BVOC emission potential, respectively, in the MEGAN model. Therefore, multiple satellite-based LAI and LC products were examined in this study to investigate the uncertainties associated with the LAI and LC inputs. Section 2 introduces the models and datasets used in this study.
In Sect. 3, we elaborate our BVOC emission inventory as well as the sensitivities of the model to different satellite inputs. We present our conclusions in Sect. 4.

\section{Methodology}

\subsection{Model description}

The BVOC emission rate in MEGAN is calculated as follows (Guenther et al., 2006):

emission $=[\varepsilon] \cdot[\gamma] \cdot[\rho]$,

where $\varepsilon$ is a factor that accounts for the emission rates of different compounds under standard canopy conditions, $\gamma$ is an activity factor that accounts for the environmental variance, and $\rho$ is a factor that accounts for chemical and physical losses in the plant canopy layer.

\subsubsection{Emission factors}

The standard emission rates in MEGAN adopt the canopyscale emission factors $\left(\mu \mathrm{g} \mathrm{m}{ }^{-2} \mathrm{~h}^{-1}\right)$, which are converted from the measured leaf-scale emission factors $\left(\mu \mathrm{g} \mathrm{m}^{-2} \mathrm{~h}^{-1}\right)$. The leaf-scale emission factor, leaf mass per area (LMA, $\mathrm{g} \mathrm{m}^{-2}$ ) and the standard environmental factor were used to convert the leaf-scale emission factors to canopy-scale emission factors (Leung et al., 2010; Guenther et al., 2006). In MEGAN, the $\varepsilon$ can be described by either the specific tree species map or the plant functional type (PFT) map (Guenther et al., 2006). In this study, we adopted six PFTs to explain the standard emission factors: broadleaf trees, needleleaf trees, shrubs, grass, corn and other crops. Moreover, we modified the standard emission factor of isoprene for every PFT according to local field measurements from previous publications (Wang et al., 2003; Klinger et al., 2002). Based on the area data of diverse tree species from the eighth NFRS (Table S1 in Supplement), which came from Ren et al. (2017), the emission factors of isoprene for the PFTs mentioned above are calculated as

$\varepsilon_{j}=\sum \varphi_{i} \mathrm{LMA}_{i} \frac{s_{i}}{s_{j}}$

where $\varepsilon_{j}$ is the canopy-scale emission factor of the PFT species $j, \phi_{i}$ is the leaf-scale emission factor for the vegetation species $i$, and the $S_{i} / S_{j}$ represents the area proportion of vegetation species $i$ in PFT $j$.

Due to the lack of measurements of emission factors in the local area, the default emission factors of MEGAN v2.1 were used for all other VOCs. Table 1 shows the original and adjusted standard emission factors of isoprene.

\subsubsection{Environmental activity factor}

The environmental activity factor accounts for the effects of leaf age, canopy meteorological environment and soil mois- 
Table 1. Adjusted (original) isoprene emission factors (EF, $\mu \mathrm{g} \mathrm{m}^{-2} \mathrm{~h}^{-1}$ ) for each plant functional type (PFT).

\begin{tabular}{ccccccc}
\hline PFT & $\begin{array}{c}\text { Broadleaf } \\
\text { trees }\end{array}$ & $\begin{array}{c}\text { Needleleaf } \\
\text { trees }\end{array}$ & Shrub & Grass & $\begin{array}{c}\text { Other } \\
\text { crops }\end{array}$ & Corn \\
\hline EF & $6510(10000)$ & $64(600)$ & $544(4000)$ & $14(800)$ & $2(50)$ & $1(1)$ \\
\hline
\end{tabular}

ture in MEGAN, and it can be expressed as

$\gamma=\gamma_{\mathrm{CE}} \cdot \gamma_{\mathrm{age}} \cdot \gamma_{\mathrm{SM}}$

where $\gamma_{\mathrm{CE}}$ accounts for variations in the canopy meteorological conditions, $\gamma_{\text {age }}$ describes the effect of leaf age, and $\gamma_{\mathrm{SM}}$ accounts for the impact of soil moisture.

Temperature and photosynthetically active radiation (PAR) are the main canopy meteorological variables that affect BVOC emissions. The emission of isoprene was modeled as fully light and temperature dependent according to the algorithms of isoprene emission conditions described by Guenther et al. (2012). Approximately $10 \%$ of monoterpenes and $50 \%$ of sesquiterpenes were treated as light- and temperature-dependent, and the others were treated as temperature-dependent species (Sakulyanontvittaya et al., 2008). The moisture factor $\gamma_{\mathrm{SM}}$ was only considered for the isoprene emission. The corresponding canopy models were adopted to calculate the sunlit and shaded leaves' temperature and light scattering of each PFT (Guenther et al., 1999, 2006). The details of the algorithms used for isoprene and monoterpenes can be found in Guenther et al. (2012) and Sakulyanontvittaya et al. (2008).

\subsection{Data and simulation description}

In this study, we used a mesoscale weather model to provide the meteorological conditions. Due to the lack of direct observations of canopy emissions, we varied the input conditions to investigate the sensitivity of the simulation to the emission inventory. Three PFT and three LAI datasets were adopted to investigate the impact of these inputs.

\subsubsection{WRF meteorological simulation}

The Weather Research and Forecasting (WRF) v3.3.1 (Skamarock et al., 2008) model was used to provide the meteorological conditions. The initialization field and boundary conditions for WRF are provided by the National Centers for Environmental Prediction (NCEP) FNL (Final) Operational Global Analysis data (National Centers for Environmental Prediction, 2000) (https://rda.ucar.edu/datasets/ds083.2/). The boundary conditions are updated every $6 \mathrm{~h}$. The model domain contained three horizontally nested grids with the spatial resolution of 27, 9 and $3 \mathrm{~km}$ and 31 vertical layers, including four layers of soil from the Noah land surface model (Tewari et al., 2004). The $3 \mathrm{~km}$ horizontal grid covered Beijing and was used for the BVOC emission inventory. The

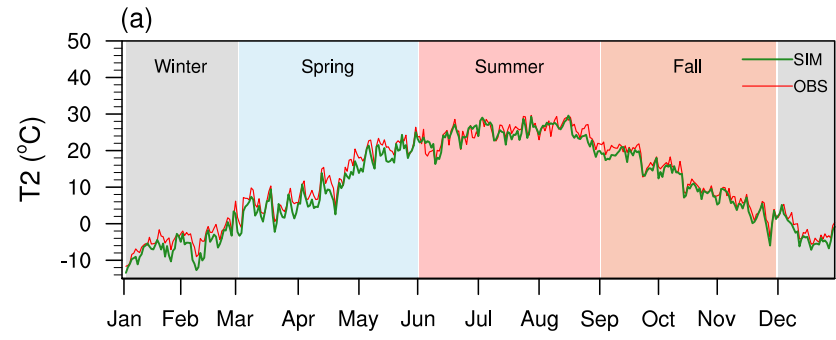

(b)

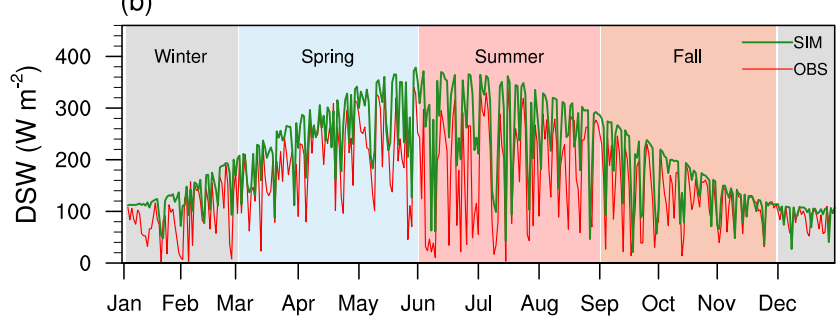

Figure 1. Time series plots of (a) station-averaged simulated and in situ $2 \mathrm{~m}$ temperature (T2) as well as (b) simulated and in situ downward shortwave radiation (DSW) at the Beijing station.

WRF model was initialized at 12:00 UTC, and the first $12 \mathrm{~h}$ was spin-up time. The data of the period from 00:00 UTC to 23:00 UTC UTC in the second day was cut and merged to estimate the BVOC emissions. The merged file was processed by the Meteorology-Chemistry Interface Processor (MCIP) (Otte and Pleim, 2010) tool to provide meteorological conditions for MEGAN. The physical options used for the WRF model are presented in Table $\mathrm{S} 2$.

The temperature at $2 \mathrm{~m}$ height (T2) simulated by WRF was primarily verified by in situ data from 19 monitoring sites in the Beijing region, and the daily downward shortwave radiation (DSW) was also validated using the in situ data from the Beijing station. Table 2 presents the verification statistics of average hourly T2 among all sites and DSW of the Beijing station, and Fig. 1 shows the time series of stationaveraged daily T2 and DSW. As shown in Table 2, the mean error (ME), mean bias (MB), correlation coefficient $(r)$ and root-mean-square error (RMSE) of station-averaged hourly $\mathrm{T} 2$ series are $2.11,-1.38,0.98$ and $2.57^{\circ} \mathrm{C}$, respectively. The $r$ values in summer (0.87) and winter (0.86) are relatively lower than those in spring (0.97) and fall (0.97), and the simulation shows cooling biases of $-2.04,-0.45,-1.19$ and $-2.1{ }^{\circ} \mathrm{C}$ in spring, summer, fall and winter, respectively. The ME, MB, $r$ and RMSE of the whole-year DSW series 
Table 2. Verification statistics of hourly temperature at $2 \mathrm{~m}$ height (T2) and daily downward shortwave radiation (DSW). ME, MB and RMSE are abbreviations for mean error, mean bias and root-mean-square error, respectively.

\begin{tabular}{llrrrrrr}
\hline Variable & Season & \multicolumn{2}{c}{ Mean } & ME & MB & $r$ & RMSE \\
\cline { 3 - 5 } & & Obs. & Sim. & & & & \\
\hline \multirow{5}{*}{ T2 $\left({ }^{\circ} \mathrm{C}\right)$} & Spring & 12.59 & 10.55 & 2.43 & -2.04 & 0.97 & 2.84 \\
& Summer & 25.08 & 24.63 & 1.72 & -0.45 & 0.87 & 2.21 \\
& Fall & 12.23 & 11.04 & 1.82 & -1.19 & 0.97 & 2.15 \\
& Winter & -4.04 & -6.14 & 2.67 & -2.10 & 0.86 & 3.18 \\
& Year & 13.06 & 11.68 & 2.11 & -1.38 & 0.98 & 2.57 \\
\hline \multirow{5}{*}{ DSW $\left(\mathrm{W} \mathrm{m}^{-2}\right)$} & Spring & 205.54 & 262.71 & 59.66 & 57.17 & 0.75 & 75.94 \\
& Summer & 184.36 & 269.59 & 88.14 & 85.23 & 0.77 & 106.61 \\
& Fall & 124.40 & 155.34 & 34.71 & 30.94 & 0.79 & 48.54 \\
& Winter & 93.91 & 132.96 & 41.86 & 39.05 & 0.69 & 53.14 \\
& Year & 157.60 & 212.35 & 57.77 & 54.76 & 0.81 & 76.80 \\
\hline
\end{tabular}

are $57.77,54.76,0.81$ and $76.80 \mathrm{~W} \mathrm{~m}^{-2}$, and the simulation of DSW exhibits overestimation of 57.17, 85.23, 30.94 and $39.05 \mathrm{~W} \mathrm{~m}^{-2}$ in spring, summer, fall and winter, respectively. The detailed statistics of hourly $\mathrm{T} 2$ of specific stations are given in Table S3. Across all sites, Tongzhou, Daxing, and Fangshan have the most obvious underestimates of surface temperature, with high negative biases of $-5.28,-5.36$ and $-4.68^{\circ} \mathrm{C}$, respectively. Figure 2 shows the location of all sites, with the MB of $\mathrm{T} 2$ indicated by the color scale, and these sites are located in the suburban regions of Beijing, which are experiencing fast urbanization and lower BVOC emissions. WRF did not simulate the urban heat island phenomenon in these regions. The main source of BVOCs is the rural forest around Beijing, and Table S3 as well as Fig. 2 indicate relatively good simulation among the sites in the rural region; therefore, the simulation bias of the suburban regions can be expected to have little impact on the estimate of whole BVOC emissions.

\subsubsection{Satellite datasets}

The PFT and LC datasets include the Finer Resolution Observation and Monitoring of Global Land Cover (FROM-GLC) (Gong et al., 2013; Yu et al., 2014), the Moderate-Resolution Imaging Spectroradiometer (MODIS) MCD12Q1 PFT products (Friedl et al., 2010), and the Climate Change Initiative Land Cover (CCI LC) products (ESA, 2017). Three LAI data products are adopted as LAI input, including the Global LAnd Surface Satellite (GLASS) (Xiao et al., 2014, 2016), MODIS MCD15A2 version 5 (Knyazikhin et al., 1999), and GEOland (GEO) v2 (Baret et al., 2013; Verger et al., 2014b) LAI products. The LC datasets were regridded to the WRF grid by calculating the area fraction of each PFT, and the LAI datasets were converted from original grids to WRF grids by calculating the area mean LAI in the WRF grids.

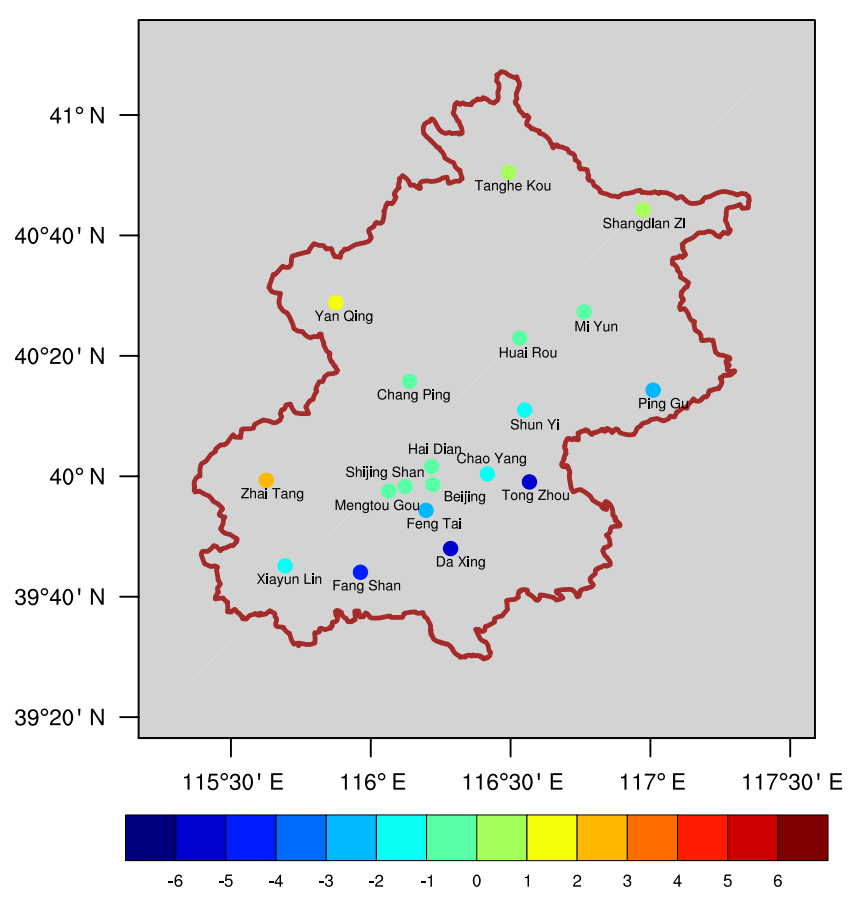

Figure 2. Spatial distribution of the mean bias $(\mathrm{MB})$ of temperature (T2) from all available sites.

FROM-GLC is the first global LC product with $30 \mathrm{~m}$ spatial resolution (Gong et al., 2013). It is based on Thematic Mapper (TM)/Enhanced Thematic Mapper (ETM) images and uses images from MODIS and Google Earth as references. Because the higher spatial resolution captures a more detailed distribution of PFTs, we used the latest version FROM-GLC-AGG (Yu et al., 2014) as the baseline PFT input. The spatial resolutions of the other two global LC products used to study the impact of the PFT inputs, MODIS MCD12Q1 and CCI LC, are 500 and $300 \mathrm{~m}$, respectively. The benchmark years of FROM, MODIS and CCI LC are 
Table 3. The area fractions of different plant functional types (PFTs) in Beijing from the three land cover datasets.

\begin{tabular}{lccrrrr}
\hline & $\begin{array}{c}\text { Broadleaf } \\
\text { trees }\end{array}$ & $\begin{array}{c}\text { Needleleaf } \\
\text { trees }\end{array}$ & Shrub & Grass & $\begin{array}{r}\text { Other } \\
\text { crops }\end{array}$ & Corn \\
\hline FROM-GLC & $27.3 \%$ & $7.3 \%$ & $11.3 \%$ & $11.9 \%$ & $3.6 \%$ & $23.7 \%$ \\
MODIS LC & $30.3 \%$ & $6.6 \%$ & $2.3 \%$ & $15.8 \%$ & $21.5 \%$ & $11.8 \%$ \\
CCI LC & $20.0 \%$ & $6.3 \%$ & $8.4 \%$ & $16.6 \%$ & $7.6 \%$ & $5.6 \%$ \\
\hline
\end{tabular}
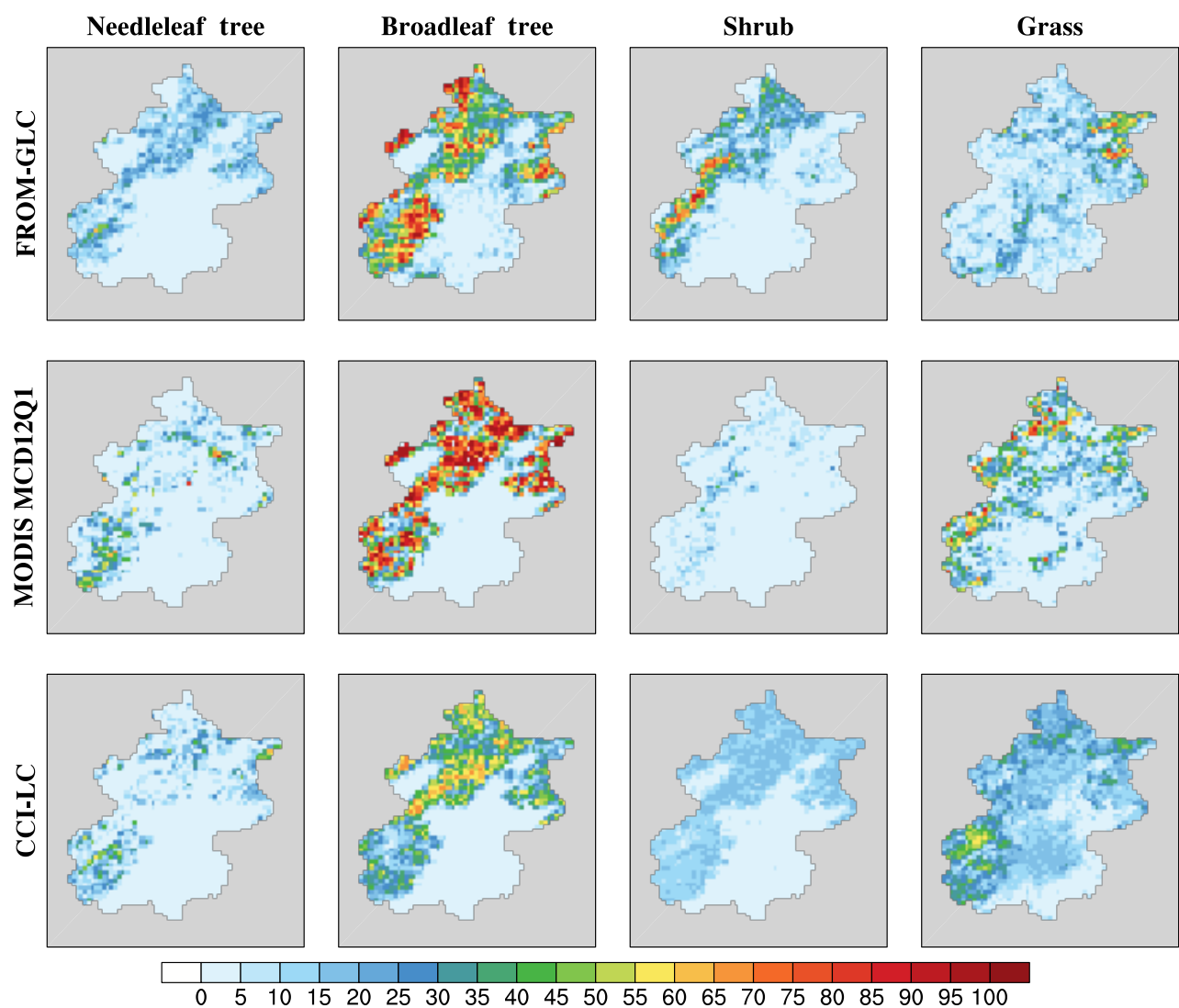

Figure 3. Spatial distribution of the proportions of plant functional types (PFTs) in model grids in the three land cover inputs.

2010, 2013 and 2013, respectively. Since the forests would not obviously change in 3 years, the FROM PFT used to calculate the BVOC emissions with other inputs was for year 2013. The PFT map layer of the MODIS MCD12Q1 product was directly used. CCI LC uses the default cross-walking table given by Poulter et al. (2015) to convert the LC class maps to PFT maps. The FROM-GLC conversion process used the class legend description, with each LC type being classified into the corresponding PFT. The PFT proportions of the three LC products are presented in Table 3. All three products have similar percentages of needleleaf trees, but different percentages of broadleaf trees. The CCI LC has lower broadleaf tree coverage compared to the other two products due to the impact of the cross-walking table. Figure 3 shows the spatial distribution of the four main PFTs in the model grids of the LC products. As shown in Fig. 3, the three datasets have similar distributions, but differ in forest density. Because of the high emission factors of broadleaf trees, the highest broadleaf tree density of the MODIS LC data implies the highest emission density. Considering the high biomass and emission factors, the local broadleaf trees could lead to a considerable emission potential. In contrast, the distributions of the shrub and grass PFTs show higher variability than the tree PFTs, but the low emission factors limit their impacts on the estimate of terpenoid emissions.

Three different LAI datasets were adopted in this study: the GLASS v1.1, MODIS MCD15A2 and GEO v2 LAI products. All three datasets have a spatial resolution of $1 \mathrm{~km}$. The temporal resolutions of GLASS and MODIS are both 8 days, and that of GEO v2 is 10 days. The GLASS v1.1 LAI products are retrieved from reprocessed Advanced Very High Resolution Radiometer (AVHRR) and MODIS reflectance 
(a) GLASS: JJA

(b) MODIS: JJA

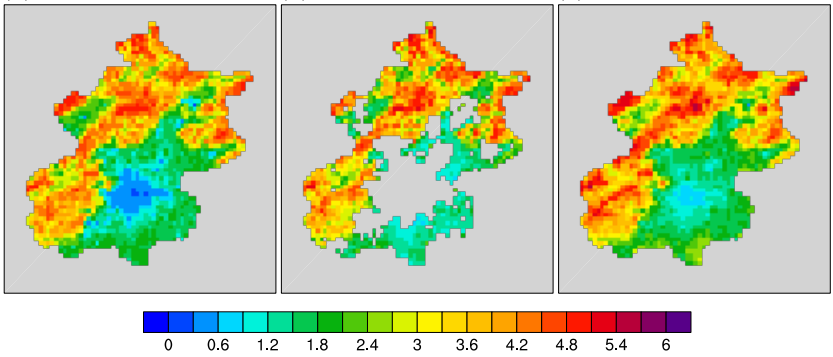

Figure 4. The average spatial distribution of (a) GLASS, (b) MODIS and (c) GEO v2 LAI in summer (June, July and August; JJA).

data using the general regression neural network (GRNN) (Xiao et al., 2014, 2016), which was trained by the fused LAI from the MODIS and CYCLOPES LAI products. The GEO v1 adopts the Neural Network trained by the MODIS and CYCLOPES fused LAI to derive the LAI from the reflectance data from the SPOT/VEGETATION sensor (Baret et al., 2013). Based on GEO v1, the later GEO v2 employs a filtering approach to eliminate the outliers as well as Savitzky-Golay and climatological temporal smoothing and gap filling methods to ensure consistency and continuity (Verger et al., 2014a). Due to the diversity of satellite data sources and algorithms, these three datasets are treated as dependent datasets and were used to study the impact of different satellite LAI inputs. Figure $4 a-c$ show the spatial distribution of the three LAI products in the model grid in summer. Since MODIS MCD15A2 uses the vegetation canopy radiation model to produce LAI products (Knyazikhin et al., 1999), the region assigned as non-pure vegetation types leads to missing values in the MODIS MCD12 Q1 LC products. Thus, the MODIS MCD15A2 LAI product has a bigger mask area in suburban areas and near water, which could lead directly to the loss of BVOC emissions in these areas. Figure 5 shows the monthly average LAI values of trees and grasses of the three products based on the MODIS MCD12Q1 LC. Only the grid cells in the region over which the MODIS MCD15A2 LAI is valid were taken into account. According to Fig. 5, the three LAI products have nearly the same trend in LAI values for trees, and the GEO v2 product has the highest LAI from May to September. The MODIS MCD15A2 product has the lowest LAI of the three products for the tree and herb vegetation. The peak LAI of trees occurs in July for all three products, and the mean LAIs of the three products during the winter seasons are all below 1 because of the low biomass of local deciduous tree species. The direct validations by Xiao et al. (2016) showed that of the three products, the GLASS LAI is most consistent with observations. Therefore, we treated the GLASS LAI as the most accurate LAI and it was used in the baseline experiments.

Table 4 presents the configurations of the simulation experiments. The baseline experiment (E1) used the FROM

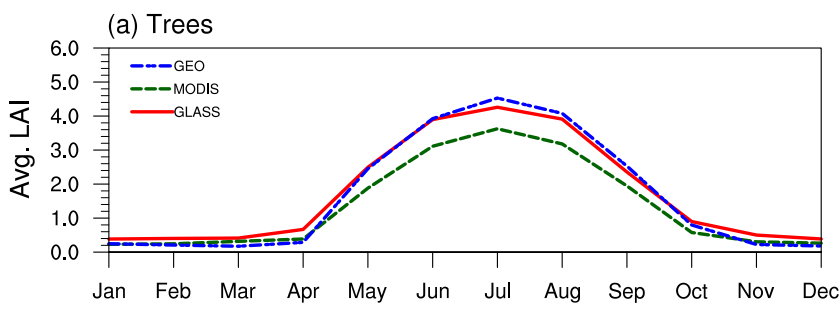

(b) Grass and crop

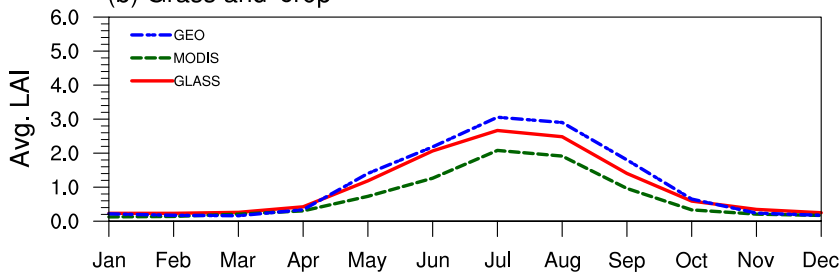

Figure 5. The monthly average leaf area index (LAI) values of (a) trees and (b) herbs in the three LAI products.

Table 4. The simulation experiment configurations. E1 is the baseline experiment, and E1-E3 were used to investigate the impact of leaf area index inputs. The impact of different plant functional type (PFT) inputs was investigated by E1, E4 and E5.

\begin{tabular}{lll}
\hline & Land cover & Leaf area index \\
\hline E1 (baseline) & FROM & GLASS v1.1 \\
E2 & FROM & GEO v2 \\
E3 & FROM & MODIS MCD15 \\
E4 & MODIS MCD12Q1 & GLASS v1.1 \\
E5 & CCI LC & GLASS v1.1 \\
\hline
\end{tabular}

PFT and GLASS LAI as inputs. Experiments E1-E3 used the same PFT input and varied the LAI inputs to investigate the impacts of the different LAI inputs. The effect of different PFT inputs was investigated in experiments E1, E4 and E5, which all used the same GLASS LAI input but used different LC datasets.

\section{Results and description}

MEGAN v2.1 can output 20 basic compounds, which can be divided into 150 VOC species (Guenther et al., 2012). In this study, the VOC species are divided into four groups: isoprene, monoterpenes, sesquiterpenes, and other VOCs. Monoterpenes include myrcene, sabinene, limonene, 3 -carene, $\alpha$ - $\beta$-ocimene, $\beta$-pinene, $\alpha$-pinene, and other monoterpenes, and the sesquiterpenes include $\alpha$-farnesene, $\beta$-caryophyllene and other sesquiterpenes. The following sections are largely focused on the terpenoids because of their high reactivity and because they are better understood than the other VOCs, which are associated with larger uncertainties. 
Table 5. The total annual BVOC emissions $(\mathrm{Gg})$ from all experiments.

\begin{tabular}{rcrccc}
\hline & Isoprene & Monoterpenes & Sesquiterpenes & Other VOCs & SUM \\
\hline E1 & 28.5 & 11.1 & 1.4 & 34.9 & 75.9 \\
E2 & 27.7 & 11.0 & 1.4 & 35.6 & 75.7 \\
E3 & 23.1 & 9.8 & 1.2 & 27.7 & 61.8 \\
E4 & 30.2 & 9.3 & 1.2 & 35.8 & 76.5 \\
E5 & 20.6 & 8.4 & 1.0 & 26.0 & 56.0 \\
\hline
\end{tabular}
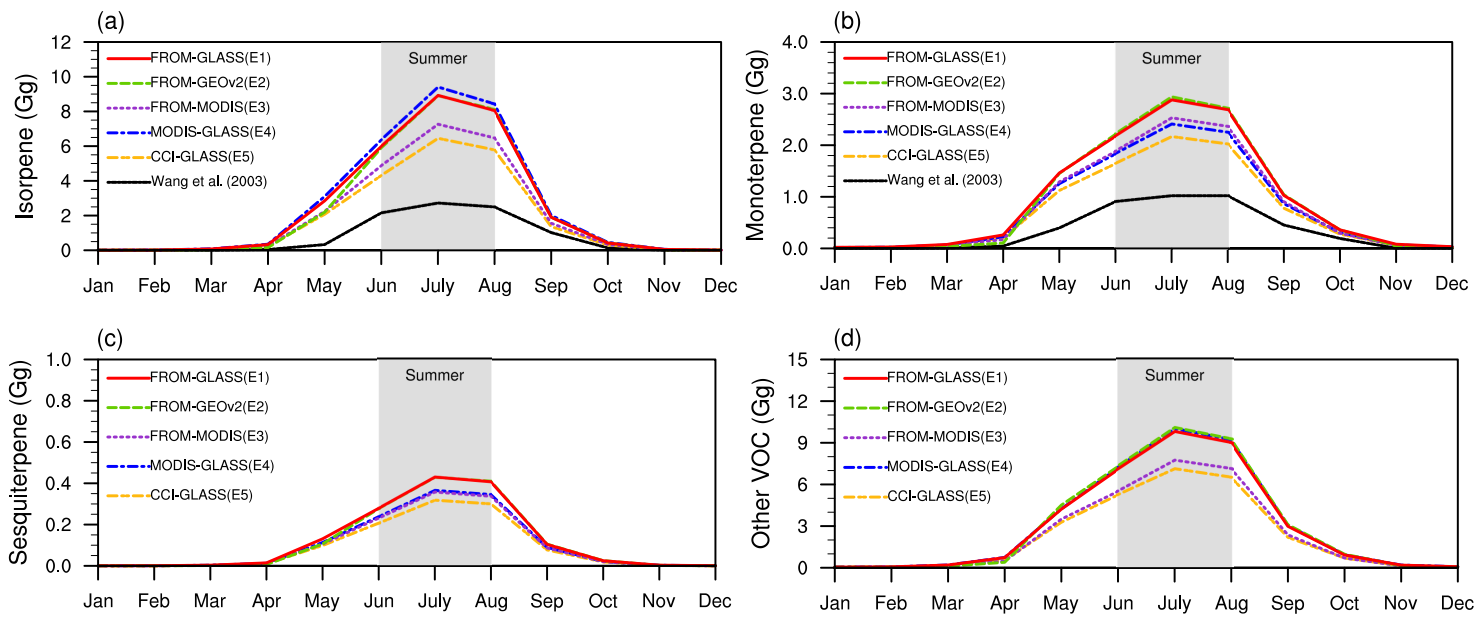

Figure 6. The temporal variability in biogenic volatile organic compounds (BVOCs) in all simulation experiments.

\subsection{Quantity of BVOC emissions}

According to the baseline experiment (E1), the quantity of BVOCs emitted annually in Beijing is $75.9 \mathrm{Gg}$; isoprene, monoterpenes, sesquiterpenes and other VOCs make up 37.6, 14.6, 1.8 and $46.0 \%$ of the total, respectively. Table 5 presents the annual emission results of all experiments. E2 and $\mathrm{E} 4$ have similar total emissions at 75.7 and $76.5 \mathrm{Gg}$, respectively, while E3 and E5 have lower emissions at 61.8 and $56.0 \mathrm{Gg}$, respectively. The GEO LAI total emissions are more similar to the E1 results than those of the MODIS LAI. However, if only grid cells over which the MODIS LAI has no missing values are taken into account, the total BVOC emissions of E1-E3 are $63.5,62.6$ and $61.8 \mathrm{Gg}$; i.e., the MODIS MCD15A2 LAI and the GEO LAI lead to 1.4 and $2.6 \%$ differences with E1, respectively. The problem is that the E1 BVOC emissions in the region where the MODIS LAI has missing values account for $16.3 \%$ of the total $\mathrm{E} 1$ emissions. Considering the importance of BVOC emissions in suburban areas on air quality, the GEO and GLASS LAI may be better choices for use in BVOC estimation for regional air quality simulation and forecasting. In particular, the estimates obtained using the GEO LAI for specific BVOC species all differ from E1 by less than $4 \%$.

The different PFT inputs used in experiments E4 and E5 lead to a $0.6 \%$ increase and a $26.3 \%$ decrease in total BVOC emissions, respectively. The extensive broadleaf tree cover in the MODIS MCD12Q1 LC dataset leads to higher BVOC emissions by way of a higher emission rate.

In this study, the cross-walking table used in the CCI LC to convert LC classes to PFTs contains a scale factor that increases the proportion of grasses and decreases the proportions of other PFTs. This process leads to the total BVOC emissions in E4 being approximately $75 \%$ of the total E1 emissions. For E1, E4 and E5, the high spatial resolution $(30 \mathrm{~m})$ of FROM can compensate to some extent for the mixed pixel problem of the MODIS $(500 \mathrm{~m})$ and CCI LC $(300 \mathrm{~m})$ medium-resolution sensor products in this study.

\subsection{Temporal variations}

Figure 6 shows the temporal variations in BVOC emission of the four groups for all experiments (E1 to E5). The temporal distribution is similar in all experiments. Summer and winter emissions account for 74.9-76.9 and 0.26-0.40\%, respectively, of annual BVOC emissions. The differences among the inputs do not have a significant effect on the temporal variability in the BVOC emissions estimated by the MEGAN model. Moreover, the ratio of BVOC emissions between the summer and winter seasons is 185-295, compared with a ratio of 9.77 in the Pearl River Delta region (Wang et al., 2011) and 4.9 in Hong Kong (Leung et al., 2010). In temperate regions like Beijing, BVOC emissions display a very strong 


\section{E1 E1-E2 E1-E3 E1-E4 E1-E5}
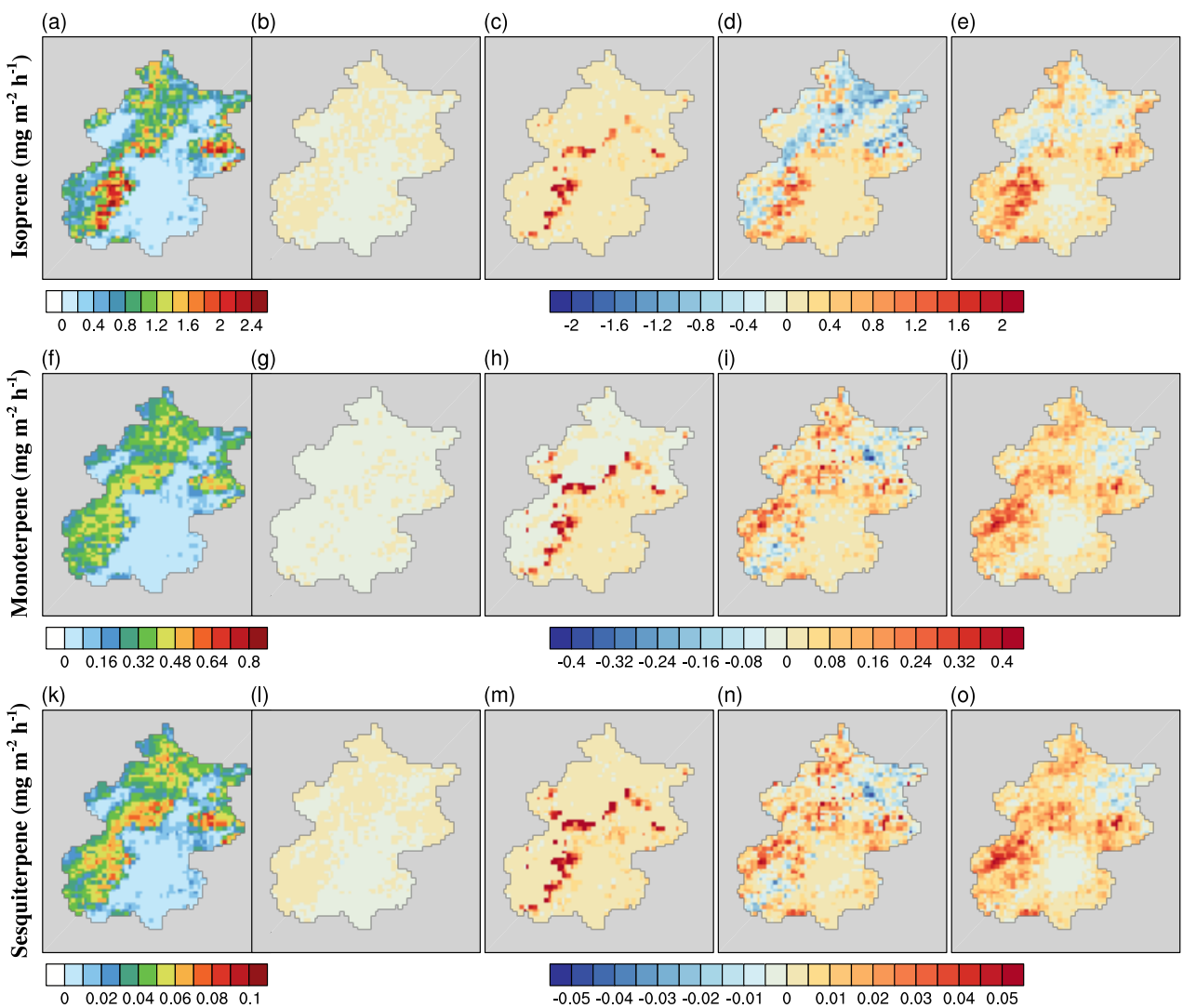

Figure 7. The spatial distribution of average emissions of the three main VOC species in summer.

annual cycle, as there are almost no BVOC emissions in winter owing to the low winter biomass of temperate deciduous trees as well as low temperatures in winter. Additionally, the emissions differ more among experiments in summer than in winter because of the high emission amount in summer. The black lines represent the previously estimated emissions of isoprene and monoterpenes for 1998 from Wang et al. (2003). As shown in Fig. 6, our results have similar temporal variability to the Wang et al. (2003) results, but all the results in this study are higher than their estimate. The ratios between our summer estimates and the results in Wang et al. (2003) for summer are 2.24-3.2 and 1.97-2.66 for isoprene and monoterpenes, respectively. There are multiple reasons for this large discrepancy between the two studies. Apart from differences in the inputs of the two studies, the significant development of forest and vegetation in the entire region during the last 2 decades may have played a significant role in the increase in BVOC emissions, leading to the higher estimates in this study. Ghirardo et al. (2016) used field surveys of tree numbers to estimate that BVOC emissions in the megacity region of Beijing doubled from 2005 to 2010. Furthermore, the increasing trend in BVOC emissions in Beijing is consistent with model estimates by Ren et al. (2017).

\subsection{Spatial distribution}

Since the contribution of summer BVOC emissions to the total annual emissions can reach about $75 \%$ and photochemistry is very active in summer, our analysis of spatial distributions is mainly focused on summer BVOC emissions.

Figure 7 displays the spatial distribution of the average emission rates of isoprene, monoterpenes and sesquiterpenes during summer in E1 as well as the difference between E1 and the other experiments. According to Fig. 7a, f and k, the BVOC emission hotspots are concentrated in the rural forest region around the city of Beijing. Despite the updating frequency of the GLASS datasets being 8 days and that of GEO v2 being 10 days, isoprene, monoterpenes and sesquiterpenes in E1 and E2 have nearly identical spatial distributions. As mentioned in Sect. 2.2.2, the mask area of the MODIS LAI directly leads to missing BVOC emissions in the suburban area; consequently, the relatively low LAI values also lead to the slight decreases in isoprene, monoterpenes and sesquiterpenes (Fig. $7 \mathrm{c}, \mathrm{h}$ and $\mathrm{m}$ ).

The spatial distribution of BVOC emissions in E4 and E5 is conspicuously different than in E1, in keeping with differences in the PFT distributions in the inputs (Fig. 3). E4 shows lower isoprene emissions than $\mathrm{E} 1$ in the northeast, the 
Huairou District, and Miyun County in Beijing, and higher isoprene emissions in the west, the Mentougou District, and the Haidian District, which is likely due to the differences in the broadleaf tree distribution, the PFT with the highest emission potential, between the inputs for E1 and E4. The E5 experiment, which used the CCI LC, shows similar results to the E4 experiment with MODIS LC for isoprene, although the higher isoprene emissions in the west are more obvious for E5, reaching 1.2-1.8 $\mathrm{mg} \mathrm{m}^{-2} \mathrm{~h}^{-1}$. E4 and $\mathrm{E} 5$ both estimate higher monoterpene and sesquiterpene emissions than E1 at the western edge of the boundary of Beijing and lower emissions in the northeast in Miyun County.

Overall, the main BVOC emission pools are the regions to the west and northeast of the megacity, such that the city is surrounded by the BVOC pools. In terms of $\mathrm{O}_{3}$, although the forest area lacks $\mathrm{NO}_{x}$ emissions, the isoprene oxidation products, e.g., formaldehyde, could be transported to the city region and affect urban air quality (Geng et al., 2011); similarly, $\mathrm{NO}_{x}$ from the urban area could be transported to the rural area and form $\mathrm{O}_{3}$.

\subsection{Discussion}

\subsubsection{Sensitivity of BVOC emissions to LAI and PFT}

To study the effect of the LAI input on BVOC emissions, we adopted three independent satellite-derived LAI datasets. According to the direct validation by Xiao et al. (2016), the GLASS and the GEO LAIs are generally of better quality than the MODIS MCD15A2 LAI. Although the average MODIS MCD15A LAI is lower than the GLASS and GEOv2 LAIs, the comparison of BVOC emissions with E1 in the region over which MODIS is valid (i.e., no missing values) showed that use of the GEOv2 and MODIS LAI input led to decreases of only 1.4 and $2.6 \%$, respectively. The discrepancies between different LAI inputs do not obviously affect the estimate of BVOC emissions in Beijing. However, considering the missing values in the MODIS MCD15A2 LAI, using the GLASS LAI and the GEO LAI is a better solution than using interpolation to fill in the missing values in the MODIS LAI.

The discrepancies of PFT datasets are relative larger than those among the LAI datasets; therefore, the corresponding BVOC emission results showed more notable differences induced by PFT input. Which LC dataset is used in the model significantly affects the BVOC emission estimates (Zhao et al., 2016; Wang et al., 2011). There are two major sources of uncertainty in the PFTs: the accuracy of the LC map and the cross-walking table used to convert the LC classes to PFTs (Hartley et al., 2017). We used 61 sample points in Beijing and the surrounding area from the Land Cover Validation Dataset by Zhao et al. (2014) as primary validation for the LC datasets. The validation samples were collected from TM/ETM images for 2009-2011. The accuracies of the FROM, MODIS and CCI LC datasets are 59.67, 54.1 and
$50.81 \%$, respectively. Since FROM LC has the same benchmark period as the validation dataset and similar spatial resolution, the FROM LC displayed better accuracy than the other two products. The validation results can only coarsely assess the accuracy of the LC datasets. The advantage of the high-resolution data is that they diminish the uncertainties associated with mixed pixels in the medium-resolution LC map, which relies on the cross-walking table to convert the LC classes to PFTs.

The uncertainties associated with the cross-walking table are more evident in CCI LC. The cross-walking table used in E5 is the default table designed for the global scale. Therefore, two more sensitivity experiments were designed using the "minimum biomass" (minCW) and "maximum biomass" (maxCW) cross-walking tables provided by Hartley et al. (2017) for CCI LC to examine the uncertainties associated with the cross-walking table. As shown in Table 6, the area fractions of broadleaf and needleleaf trees were 29.9 and $8.8 \%$ in the maxCW simulation, respectively, which are similar to those of FROM and MODIS (Fig. S1 in Supplement), while the minCW simulation led to relatively low area fractions of 10.9 and $3.7 \%$ for broadleaf trees and needleleaf trees, respectively. The BVOC emission estimates with diverse cross-walking tables for CCI LC are shown in Table 7. Compared with the results of $\mathrm{E} 5$, the $\operatorname{maxCW}$ and $\operatorname{minCW}$ simulations led to a $48.1 \%$ increase and a $44.7 \%$ decrease in isoprene and a $20.2 \%$ increase and a $33.3 \%$ decrease in monoterpene, respectively, indicating the strong effect of the cross-walking table on the BVOC estimates, which is more significant for the medium-resolution map. But for a highresolution LC map based on TM/ETM images like FROM, high spatial resolution could diminish the uncertainty from cross-walking processes. Furthermore, the BVOC emissions in the maxCW experiment are similar to the results of $\mathrm{E} 1$ with FROM LC and E4 with MODIS LC: a $7.0 \%$ increase in isoprene and $9.0 \%$ decrease in monoterpenes compared to $\mathrm{E} 1$, and a $1.0 \%$ increase in isoprene and $8.6 \%$ increase in monoterpenes compared to E4.

\subsubsection{Comparison with previous studies}

Table 8 presents the BVOC emissions in Beijing estimated in this study and in previous studies. To facilitate comparison, the total emissions $(\mathrm{Gg})$ are converted into the area average emission intensity $\left(\mathrm{g} \mathrm{m}^{-2}\right)$. As showed in Table 8 , the isoprene results in this study are higher than the results in Wang et al. (2003), Klinger et al. (2002) and Ren et al. (2017) but lower than the results for 2010 in Ghirardo et al. (2016) and the calculation by Li and Xie (2014). All the monoterpene results, except for the results of Wang et al. (2003) and those of Ghirardo et al. (2016) for 2005, are in the range of 0.51-0.68.

The results of Klinger et al. (2002) as well as Li and Xie (2014) are subsets of the inventory for the whole China region, while the others are more thorough and concentrate specifically on the Beijing region. Ren et al. (2017) used 
Table 6. The area fractions of different plant functional types (PFTs) in Beijing from the CCI LC with maximum biomass, minimum biomass and default cross-walking tables.

\begin{tabular}{lcccccc}
\hline & $\begin{array}{c}\text { Broadleaf } \\
\text { trees }\end{array}$ & $\begin{array}{c}\text { Needleleaf } \\
\text { trees }\end{array}$ & Shrub & Grass & $\begin{array}{c}\text { Other } \\
\text { crops }\end{array}$ & Corn \\
\hline Max biomass & $29.9 \%$ & $8.8 \%$ & $3.4 \%$ & $15.1 \%$ & $7.6 \%$ & $3.8 \%$ \\
Default (E5) & $20.0 \%$ & $6.3 \%$ & $8.4 \%$ & $16.6 \%$ & $7.6 \%$ & $5.6 \%$ \\
Min biomass & $10.9 \%$ & $3.7 \%$ & $8.2 \%$ & $27.5 \%$ & $7.6 \%$ & $6.8 \%$ \\
\hline
\end{tabular}

Table 7. The estimations of BVOC emissions ( $\mathrm{Gg}$ ) by adopting CCI LC with maximum biomass, minimum biomass and default crosswalking tables.

\begin{tabular}{lcrccc}
\hline & Isoprene & Monoterpenes & Sesquiterpenes & Other VOCs & SUM \\
\hline Max biomass & 30.5 & 10.1 & 1.3 & 28.3 & 70.2 \\
Default (E5) & 20.6 & 8.4 & 1.0 & 26.0 & 56.0 \\
Min biomass & 11.4 & 5.6 & 0.7 & 24.4 & 42.1 \\
\hline
\end{tabular}

Table 8. Comparison of the average emission intensities of isoprene and monoterpenes from this study and previous publications.

\begin{tabular}{llrrr}
\hline & Year & $\begin{array}{r}\text { Area } \\
\left(\mathrm{km}^{2}\right)\end{array}$ & $\begin{array}{r}\text { Isoprene } \\
\left(\mathrm{g} \mathrm{m}^{-2}\right)\end{array}$ & $\begin{array}{r}\text { Monoterpenes } \\
\left(\mathrm{g} \mathrm{m}^{-2}\right)\end{array}$ \\
\hline Wang et al. (2003) & 1998 & 16400 & 0.54 & 0.24 \\
Klinger et al. (2002) & 2002 & 16400 & 0.96 & 0.54 \\
Li and Xie (2014) & 2003 & 16400 & 1.91 & 0.50 \\
Ghirardo et al. (2016) & 2005 (city level) & 1434 & 2.05 & 0.28 \\
Ghirardo et al. (2016) & 2010 (city level) & 1434 & 4.14 & 0.63 \\
Ren et al. (2017) & 2015 & 16400 & 1.08 & 0.66 \\
This study & 2013 & 16400 & $1.25-1.84$ & $0.51-0.68$ \\
\hline
\end{tabular}

the Global Biosphere Emissions and Interactions System (GloBEIS) model framework (Guenther et al., 1999) to calculate the BVOC emissions, while Li and Xie (2014) and this study used the MEGAN model framework. The two models adopt the same algorithms to account for the environmental conditions (mainly based on Guenther et al., 1995), but they treat the biomass and seasonal variance in different ways. The results of MEGAN are generally higher than the results of GloBEIS. Because of the local nature of this study and the effect of different resolutions, isoprene emissions in this study are slightly lower and monoterpene emissions are slightly higher than the results extracted from the national scale inventory by $\mathrm{Li}$ and Xie (2014). The sensitivity experiment using the default standard emission rates of MEGAN resulted in $80 \%$ higher isoprene emissions compared with E1, which shows that the regional results of $\mathrm{Li}$ and Xie (2014) may lead to some overestimation of the BVOC emissions.

The estimates made by Ren et al. (2017) used a specieslevel vegetation inventory based on field surveys, while this study used PFT-scale estimates based on satellite datasets, with statistically derived PFT emission factors. The former method may be more accurate than the latter since emis- sion factors differ among tree species, but it is limited by the rough process of data collection, and satellite-based inventories are more easily gridded, facilitating coupling with chemistry transport models and thus allowing further investigation of the effect of BVOCs on atmospheric chemistry. Moreover, in Ren et al. (2017) the coverage of broadleaf trees and needleleaf trees is 18.7 and $7.4 \%$, respectively, and in this study, it is $20.0-30.0$ and $6.3-7.3 \%$, respectively; i.e., the coverage of needleleaf trees, the main contributors to the emission of monoterpenes, is similar between the two studies, and thus the monoterpene emissions are relatively consistent. However, the isoprene estimates in this study are generally higher than those of Ren et al. (2017): the ratios of isoprene emissions between the two studies is $1.15-1.7$, which are similar to the ratios (1.06-1.6) of broadleaf tree area between the two studies.

Furthermore, the diversity of meteorological inputs also contributes to the discrepancies among these studies. This study as well as Li and Xie (2014), both based on MEGAN, adopted the mesoscale model as meteorological inputs, and others used the in situ data from stations. Considering the spatial diversities, e.g., terrain and landscape forcing, the meteorological model could be a reasonable approach to ac- 
count for meteorological conditions of the whole region. But the simulation bias would correspondingly lead to bias of BVOC emission estimation. Wang et al. (2011) investigated the impact of meteorological simulation bias on estimating BVOC emissions by perturbing the simulated temperature and radiation with their RMSE (T2/Radiation \pm RMSE) for the Pearl River Delta, China. And their sensitivity tests showed that the decreasing (increasing) temperature led to $-19.2 \%(+26.7 \%)$ and $-18.5 \%(+16.2 \%)$ differences in isoprene emissions and monoterpene emissions, respectively; and decreasing (increasing) radiation led to $-39.6 \%$ $(+50.7 \%)$ and $-14.3(+16.8 \%)$ differences in isoprene emissions and monoterpene emissions, respectively. These results indicate the simulation bias could affect the BVOC emissions. But not all grids contain strong simulation bias, and impact of meteorological conditions would also be limited by other conditions, e.g., standard emission factor. The simulation bias among urban or suburban regions, where the BVOC emissions are low, would not have an obvious effect on whole region emission estimation. But the evaluation results showed the overestimation of DSW in this study, which would correspondingly lead to the overestimation of lightdependent BVOC emissions.

In addition, Ghirardo et al. (2016) and Ren et al. (2017) reported an increase in BVOC emissions because of local green land development. Ghirardo et al. (2016) showed that BVOC emissions doubled in the city region of Beijing from 2005 to 2010. Furthermore, Ren et al. (2017) found an even stronger increase in the urban region due to local green policy and favorable conditions. Ghirardo et al. (2016) and Ren et al. (2017) both investigated BVOC emissions from urban green space in the Beijing region. Considering the strong anthropogenic emissions and anthropogenic forcings such as high temperatures and ozone pollution, BVOC emissions from urban green space may have a more direct and stronger impact on urban air quality than suburban and rural emissions. However, this is difficult to evaluate using a mesoscale model like MEGAN, which relies on satellite-based datasets. Therefore, the field-survey-based research discussed above may play an important role in future studies concerning the impact of urban BVOC emissions on air quality.

\section{Conclusions and future work}

The first step in investigating the effect of natural emissions on local air quality is to estimate a reliable BVOC emission inventory. In this work, we established an hourly, $3 \mathrm{~km}$ gridded inventory of BVOC emissions over Beijing in 2013 based on the latest MEGAN 2.1 model. The MEGAN model was driven by the WRF v3.3.1 model, and several different satellite LAIs and PFTs were adopted to investigate and constrain the uncertainties of these input variables. Because the FROM LC product has the highest spatial resolution, the re- sults of the experiment using the FROM LC and GLASS LAI datasets are treated as the baseline results.

1. According to the results of the baseline experiment, the total quantity of BVOCs emitted in 2013 in Beijing was $75.9 \mathrm{Gg}$, with isoprene, monoterpenes, sesquiterpenes and other VOCs accounting for 37.6, 14.6, 1.8 and $46.0 \%$ of the total, respectively. BVOC emissions in Beijing display strong temporal variability: the summer season contributes $74.9-76.9 \%$ of the total emissions while the winter season only contributes $0.26-$ $0.4 \%$ for all experiments. This is a result of the low temperatures and near-zero biomass of deciduous trees in winter.

2. Different satellite LAI inputs were adopted to investigate the impact of LAI. MODIS MCD15A2 and GEO v2 LAI led to slight decreases in total BVOC emissions of 1.4 and $2.6 \%$, respectively, over the region for which MODIS LAI is valid. The missing values in MODIS LAI led to an emission loss of $16.3 \%$ compared with $\mathrm{E} 1$, and compared to filling in the missing values by interpolation, the GEO and GLASS LAI products may be the better choice for regional BVOC emissions estimates. The differences between E1 and E2 for all BVOC species are lower than $4.0 \%$, and spatial and temporal distributions are similar between the two experiments.

3. The FROM-GLC, MODIS MCD12Q1 LC and CCI LC products were adopted to investigate the sensitivity of the model to LC data. Compared to E1, the results obtained using MODIS MCD12Q1 LC have similar total emissions and temporal variability but different spatial features. For CCI LC, sensitivity tests using different cross-walking tables illustrated that the cross-walking table used to convert LC classes to PFTs has a clear impact on the BVOC emissions estimates, with the total amount of BVOC emissions estimated ranging from 42.1 to $70.2 \mathrm{Gg}$.

4. The BVOC emissions estimates obtained in this study are much higher than earlier estimates (Wang et al., 2003; Klinger et al., 2002) and similar to those in a recent study by Ren et al. (2017). Ghirardo et al. (2016) and Ren et al. (2017) both reported the development of local green areas and the active greening policy could be an important driver stimulating increasing BVOC emissions.

Due to the lack of the BVOC measurements in the Beijing region, especially flux measurements, there is a major limitation of this work in model validation. Some BVOC measurements will be collected to enhance the credibility of the model in the future. In addition, a regional chemistry transport model will be used to investigate and evaluate the role of BVOCs on local air pollution as the next step in research. 
Code and data availability. The source code of WRF model v3.3.1 (Skamarock et al., 2008) and MEGAN v2.1 (Guenther et al., 2012) is available at http://www2.mmm.ucar.edu/wrf/users/ (last access: June 2018) and https://bai.ess.uci.edu (last access: June 2018), respectively. FROM-GLC (Gong et al., 2013; Yu et al., 2014) can be downloaded5 from the website of the Department of Earth System Science, Tsinghua University, at http://data.ess.tsinghua.edu. cn/index.html (last access: June 2018). CCI LC (ESA, 2017) can be downloaded from the website of Climate Change Initiative Program at https://www.esa-landcover-cci.org (last access: June 2018). The GLASS LAI (Xiao et al., 2014, 2016) can be obtained through the website of National Earth System Science Data Sharing Infrastructure at http://www.geodata.cn/thematicView/GLASS.html (last access: June 2018) or the website of Global Land Cover Facility, University of Maryland, at http://glcf.umd.edu/data/lai/ (last access: June 2018). The GEO v2 LAI (Baret et al., 2013; Verger et al., 2014b) is available on the website of the Copernicus Global Land Service at https://land.copernicus.eu/global/products/ (last access: June 2018). The MODIS MCDQ12 LC (Friedl et al., 2010), and MODIS MCD15A2 LAI, version 5, (Knyazikhin et al., 1999) are available on the website of Land Process Distributed Active Center at https://lpdaac.usgs.gov/dataset_discovery/modis/modis_ products_table (last access: June 2018).

Supplement. The supplement related to this article is available online at: https://doi.org/10.5194/acp-18-9583-2018-supplement.

Author contributions. QW and HW planned and organized the project. HW, HL and YW prepared the input datasets. HW and QW modelled and analysed the data. HW and QW wrote the manuscrip. HW, QW, RW and HX revised the manuscript. HC, LW, and XY reviewed and provided key comments on the paper.

Competing interests. The authors declare that they have no conflict of interest.

Acknowledgements. The National Key R\&D Program of China (2017YFC0209805), the National Natural Science Foundation of China (41305121), the National Key Fundamental Research and Development Program of China (2014CB953903), and the Fundamental Research Funds for the Central Universities funded this work. The first author thanks Bin Chen for the guidance on remote sensing datasets.

Edited by: Frank Keutsch

Reviewed by: two anonymous referees

\section{References}

Arneth, A., Niinemets, Ü., Pressley, S., Bäck, J., Hari, P., Karl, T., Noe, S., Prentice, I. C., Serça, D., Hickler, T., Wolf, A., and Smith, B.: Process-based estimates of terrestrial ecosystem isoprene emissions: incorporating the effects of a di- rect $\mathrm{CO}_{2}$-isoprene interaction, Atmos. Chem. Phys., 7, 31-53, https://doi.org/10.5194/acp-7-31-2007, 2007.

Baret, F., Weiss, M., Lacaze, R., Camacho, F., Makhmara, H., Pacholcyzk, P., and Smets, B.: GEOV1: LAI and FAPAR essential climate variables and FCOVER global time series capitalizing over existing products. Part 1: Principles of development and production, Remote Sens. Environ., 137, 299-309, https://doi.org/10.1016/j.rse.2012.12.027, 2013.

Claeys, M., Graham, B., Vas, G., Wang, W., Vermeylen, R., Pashynska, V., Cafmeyer, J., Guyon, P., Andreae, M. O., and Artaxo, P.: Formation of secondary organic aerosols through photooxidation of isoprene, Science, 303, 1173-1176, 2004.

ESA: Land Cover CCI, Product User Guide, Version 2.0, 24-44, 2017.

Friedl, M. A., Sulla-Menashe, D., Tan, B., Schneider, A., Ramankutty, N., Sibley, A., and Huang, X.: MODIS Collection 5 global land cover: Algorithm refinements and characterization of new datasets, Remote Sens. Environ., 114, 168-182, https://doi.org/10.1016/j.rse.2009.08.016, 2010.

$\mathrm{Fu}, \mathrm{Y}$. and Liao, H.: Simulation of the interannual variations of biogenic emissions of volatile organic compounds in China: Impacts on tropospheric ozone and secondary organic aerosol, Atmos. Environ., 59, 170-185, https://doi.org/10.1016/j.atmosenv.2012.05.053, 2012.

Fuentes, J. D., Lerdau, M., Atkinson, R., Baldocchi, D., Bottenheim, J. W., Ciccioli, P., Lamb, B., Geron, C., Gu, L., and Guenther, A.: Biogenic Hydrocarbons in the Atmospheric Boundary Layer: A Review, B. Am. Meteorol. Soc., 81, 1537-1576, 2000.

Gao, M., Carmichael, G. R., Wang, Y., Saide, P. E., Yu, M., Xin, J., Liu, Z., and Wang, Z.: Modeling study of the 2010 regional haze event in the North China Plain, Atmos. Chem. Phys., 16, 1673-1691, https://doi.org/10.5194/acp-16-1673-2016, 2016.

Geng, F., Tie, X., Guenther, A., Li, G., Cao, J., and Harley, P.: Effect of isoprene emissions from major forests on ozone formation in the city of Shanghai, China, Atmos. Chem. Phys., 11, 1044910459, https://doi.org/10.5194/acp-11-10449-2011, 2011.

Ghirardo, A., Xie, J., Zheng, X., Wang, Y., Grote, R., Block, K., Wildt, J., Mentel, T., Kiendler-Scharr, A., Hallquist, M., Butterbach-Bahl, K., and Schnitzler, J.-P.: Urban stress-induced biogenic VOC emissions and SOA-forming potentials in Beijing, Atmos. Chem. Phys., 16, 29012920,https://doi.org/10.5194/acp-16-2901-2016, 2016.

Gong, P., Wang, J., Yu, L., Zhao, Y., Zhao, Y., Liang, L., Niu, Z., Huang, X., Fu, H., Liu, S., Li, C., Li, X., Fu, W., Liu, C., Xu, Y., Wang, X., Cheng, Q., Hu, L., Yao, W., Zhang, H., Zhu, P., Zhao, Z., Zhang, H., Zheng, Y., Ji, L., Zhang, Y., Chen, H., Yan, A., Guo, J., Yu, L., Wang, L., Liu, X., Shi, T., Zhu, M., Chen, Y., Yang, G., Tang, P., Xu, B., Giri, C., Clinton, N., Zhu, Z., Chen, J., and Chen, J.: Finer resolution observation and monitoring of global land cover: first mapping results with Landsat TM and ETM+ data, Int. J. Remote Sens., 34, 2607-2654, https://doi.org/10.1080/01431161.2012.748992, 2013.

Guenther, A., Hewitt, C. N., Erickson, D., Fall, R., Geron, C., Graedel, T., Harley, P., Klinger, L., Lerdau, M., McKay, W. A., Pierce, T., Scholes, B., Steinbrecher, R., Tallamraju, R., Taylor, J., and Zimmerman, P.: A global model of natural volatile organic compound emissions, J. Geophys. Res., 100, 8873-8892, https://doi.org/10.1029/94jd02950, 1995. 
Guenther, A., Baugh, B., Brasseur, G., Greenberg, J., Harley, P., Klinger, L., Serça, D., and Vierling, L.: Isoprene emission estimates and uncertainties for the central African EXPRESSO study domain, J. Geophys. Res., 104, 30625-30639, https://doi.org/10.1029/1999jd900391, 1999.

Guenther, A., Karl, T., Harley, P., Wiedinmyer, C., Palmer, P. I., and Geron, C.: Estimates of global terrestrial isoprene emissions using MEGAN (Model of Emissions of Gases and Aerosols from Nature), Atmos. Chem. Phys., 6, 3181-3210, https://doi.org/10.5194/acp-6-3181-2006, 2006.

Guenther, A. B., Jiang, X., Heald, C. L., Sakulyanontvittaya, T., Duhl, T., Emmons, L. K., and Wang, X.: The Model of Emissions of Gases and Aerosols from Nature version 2.1 (MEGAN2.1): an extended and updated framework for modeling biogenic emissions, Geosci. Model Dev., 5, 1471-1492, https://doi.org/10.5194/gmd-5-1471-2012, 2012.

Hartley, A. J., MacBean, N., Georgievski, G., and Bontemps, S.: Uncertainty in plant functional type distributions and its impact on land surface models, Remote Sens. Environ., 203, 71-89, https://doi.org/10.1016/j.rse.2017.07.037, 2017.

Kavouras, I. G., Mihalopoulos, N., and Stephanou, E. G.: Formation of atmospheric particles from organic acids produced by forests, Nature, 395, 683-686, 1998.

Klinger, L. F., Li, Q. J., Guenther, A. B., Greenberg, J. P., Baker, B., and Bai, J. H.: Assessment of volatile organic compound emissions from ecosystems of China, J. Geophys. Res., 107, ACH 1611-ACH 16-21, https://doi.org/10.1029/2001jd001076, 2002.

Knyazikhin, Y., Glassy, J., Privette, J. L., Tian, Y., Lotsch, A., Zhang, Y., Wang, Y., Morisette, J. T., Votava, P., Myneni, R. B., Nemani, R. R., and Running, S. W.: MODIS Leaf Area Index (LAI) and Fraction of Photosynthetically Active Radiation Absorbed by Vegetation (FPAR) Product (MOD15), Algorithm Theoretical Basis Document, 1-71, 1999.

Leung, D., Wong, P., Cheung, B., and Guenther, A.: Improved land cover and emission factors for modeling biogenic volatile organic compounds emissions from Hong Kong, Atmos. Environ., 44, 1456-1468, 2010.

Li, L. Y. and Xie, S. D.: Historical variations of biogenic volatile organic compound emission inventories in China, 1981-2003, Atmos. Environ., 95, 185-196, https://doi.org/10.1016/j.atmosenv.2014.06.033, 2014.

Otte, T. L. and Pleim, J. E.: The Meteorology-Chemistry Interface Processor (MCIP) for the CMAQ modeling system: updates through MCIPv3.4.1, Geosci. Model Dev., 3, 243-256, https://doi.org/10.5194/gmd-3-243-2010, 2010.

Penuelas, J. and Staudt, M.: BVOCs and global change, Trends Plant Sci., 15, 133-144, https://doi.org/10.1016/j.tplants.2009.12.005, 2010.

Poulter, B., MacBean, N., Hartley, A., Khlystova, I., Arino, O., Betts, R., Bontemps, S., Boettcher, M., Brockmann, C., Defourny, P., Hagemann, S., Herold, M., Kirches, G., Lamarche, C., Lederer, D., Ottlé, C., Peters, M., and Peylin, P.: Plant functional type classification for earth system models: results from the European Space Agency's Land Cover Climate Change Initiative, Geosci. Model Dev., 8, 2315-2328, https://doi.org/10.5194/gmd8-2315-2015, 2015.

Ren, Y., Qu, Z., Du, Y., Xu, R., Ma, D., Yang, G., Shi, Y., Fan, X., Tani, A., Guo, P., Ge, Y., and Chang, J.: Air quality and health effects of biogenic volatile or- ganic compounds emissions from urban green spaces and the mitigation strategies, Environ. Pollut., 230, 849-861, https://doi.org/10.1016/j.envpol.2017.06.049, 2017.

Safieddine, S., Boynard, A., Hao, N., Huang, F., Wang, L., Ji, D., Barret, B., Ghude, S. D., Coheur, P.-F., Hurtmans, D., and Clerbaux, C.: Tropospheric ozone variability during the East Asian summer monsoon as observed by satellite (IASI), aircraft (MOZAIC) and ground stations, Atmos. Chem. Phys., 16, 10489-10500, https://doi.org/10.5194/acp-16-10489-2016, 2016.

Sakulyanontvittaya, T., Duhl, T., Wiedinmyer, C., Helmig, D., Matsunaga, S., Potosnak, M., Milford, J., and Guenther, A.: Monoterpene and sesquiterpene emission estimates for the United States, Environ. Sci. Technol., 42, 1623-1629, 2008.

Seinfeld, J. H. and Pandis, S. N.: Atmospheric Chemistry and Physics: From Air Pollution to Climate Change, 2nd edn., Wiley, 175-265, 574-632, 2012.

Skamarock, W. C., Klemp, J. B., Dudhia, J., Gill, D. O., Barker, D. M., Duda, M. G., Huang, X.-y., Wang, W., and Powers, J. G.: A description of the advanced research WRF version 3, NCAR Technical Note NCAR/TN-475+STR, 1-6, https://doi.org/10.5065/D68S4MVH, 2008.

Stavrakou, T., Müller, J.-F., Bauwens, M., De Smedt, I., Van Roozendael, M., Guenther, A., Wild, M., and Xia, X.: Isoprene emissions over Asia 1979-2012: impact of climate and land-use changes, Atmos. Chem. Phys., 14, 4587-4605, https://doi.org/10.5194/acp-14-4587-2014, 2014

Tewari, M., Chen, F., Wang, W., Dudhia, J., LeMone, M., Mitchell, K., Ek, M., Gayno, G., Wegiel, J., and Cuenca, R.: Implementation and verification of the unified NOAH land surface model in the WRF model, in: 20th Conference on Weather Analysis and Forecasting/16th Conference on Numerical Weather Prediction, American Meteorological Society, Seattle, WA, USA, available at: http://n2t.net/ark:/85065/d7fb523p (last access: June 2018), 2004.

Tie, X., Li, G., Ying, Z., Guenther, A., and Madronich, S.: Biogenic emissions of isoprenoids and NO in China and comparison to anthropogenic emissions, Sci. Total Environ., 371, 238-251, 2006.

USGS: LP DAAC: Land Processes Distributed Active Archive Center, available at: https://lpdaac.usgs.gov/dataset_discovery/ modis/modis_products_table, last access: June 2018.

Verger, A., Baret, F., and Weiss, M.: Near Real-Time Vegetation Monitoring at Global Scale, IEEE J. Sel. Top. Appl., 7, 34733481, https://doi.org/10.1109/JSTARS.2014.2328632, $2014 \mathrm{a}$.

Verger, A., Baret, F., Weiss, M., Smets, B., Camacho, F., and Lacaze, R.: GEOV2/VGT: Near real time estimation of LAI, FAPAR and cover fraction variables from VEGETATION data within Copernicus Global Land service, in: Fourth International Symposium on Recent Advances in Quantitative Remote Sensing, Valence, Spain, 2014, 2014b.

Wang, J.-L., Chew, C., Chang, C.-Y., Liao, W.-C., Lung, S.C. C., Chen, W.-N., Lee, P.-J., Lin, P.-H., and Chang, C.C.: Biogenic isoprene in subtropical urban settings and implications for air quality, Atmos. Environ., 79, 369-379, https://doi.org/10.1016/j.atmosenv.2013.06.055, 2013.

Wang, T., Ding, A., Gao, J., and Wu, W. S.: Strong ozone production in urban plumes from Beijing, China, Geophys. Res. Lett., 33, L21806, https://doi.org/10.1029/2006g1027689, 2006. 
Wang, X., Situ, S., Guenther, A., Chen, F. E. I., Wu, Z., Xia, B., and Wang, T.: Spatiotemporal variability of biogenic terpenoid emissions in Pearl River Delta, China, with high-resolution land-cover and meteorological data, Tellus B, 63, 241-254, https://doi.org/10.1111/j.1600-0889.2010.00523.x, 2011.

Wang, Y., Chen, H., Wu, Q., Chen, X., Wang, H., Gbaguidi, A., Wang, W., and Wang, Z.: Three-year, $5 \mathrm{~km}$ resolution China $\mathrm{PM}_{2.5}$ simulation: Model performance evaluation, Atmos. Res., 207, 1-13, https://doi.org/10.1016/j.atmosres.2018.02.016, 2018.

Wang, Z., Bai, Y., and Zhang, S.: A biogenic volatile organic compounds emission inventory for Beijing, Atmos. Environ., 37, 3771-3782, 2003.

Xiao, Z., Liang, S., Wang, J., Chen, P., Yin, X., Zhang, L., and Song, J.: Use of General Regression Neural Networks for Generating the GLASS Leaf Area Index Product From Time-Series MODIS Surface Reflectance, IEEE T. Geosci. Remote, 52, 209223, https://doi.org/10.1109/tgrs.2013.2237780, 2014.

Xiao, Z., Liang, S., Wang, J., Xiang, Y., Zhao, X., and Song, J.: Long-Time-Series Global Land Surface Satellite Leaf Area Index Product Derived From MODIS and AVHRR Surface Reflectance, IEEE T. Geosci. Remote, 54, 5301-5318, https://doi.org/10.1109/tgrs.2016.2560522, 2016.
Yu, L., Wang, J., Li, X., Li, C., Zhao, Y., and Gong, P.: A multi-resolution global land cover dataset through multisource data aggregation, Science China Earth Sciences, 57, 2317-2329, https://doi.org/10.1007/s11430-014-4919-z, 2014.

Zhao, C., Wang, Y., Yang, Q., Fu, R., Cunnold, D., and Choi, Y.: Impact of East Asian summer monsoon on the air quality over China: View from space, J. Geophys. Res., 115, 1063-1063, 2010.

Zhao, C., Huang, M., Fast, J. D., Berg, L. K., Qian, Y., Guenther, A., Gu, D., Shrivastava, M., Liu, Y., Walters, S., Pfister, G., Jin, J., Shilling, J. E., and Warneke, C.: Sensitivity of biogenic volatile organic compounds to land surface parameterizations and vegetation distributions in California, Geosci. Model Dev., 9, 19591976, https://doi.org/10.5194/gmd-9-1959-2016, 2016.

Zhao, Y., Gong, P., Yu, L., Hu, L., Li, X., Li, C., Zhang, H., Zheng, Y., Wang, J., Zhao, Y., Cheng, Q., Liu, C., Liu, S., and Wang, X.: Towards a common validation sample set for global land-cover mapping, Int. J. Remote Sens., 35, 4795-4814, https://doi.org/10.1080/01431161.2014.930202, 2014. 